\title{
The effectiveness of an independent anti-neoplastic medication therapy management system in ambulatory cancer patients
}

\author{
Jianping Zhang ${ }^{1 \#}$, Rong Xu ${ }^{1 \#}$, Xincai Zhao ${ }^{1}$, Yonggang Wang ${ }^{2}$, Wanhu Zhu ${ }^{1}$, Misu Xiao ${ }^{1}$, Haiyan Hu ${ }^{2}$, \\ Lina Tang ${ }^{2}$, Zan Shen ${ }^{2}$, Cheng Guo ${ }^{1}$ \\ ${ }^{1}$ Department of Pharmacy, Shanghai Jiao Tong University Affiliated Sixth People's Hospital, Shanghai, China; ${ }^{2}$ Department of Oncology, Shanghai \\ Jiao Tong University Affiliated Sixth People's Hospital, Shanghai, China \\ Contributions: (I) Conception and design: J Zhang, R Xu; (II) Administrative support: Z Shen, C Guo; (III) Provision of study materials or patients: Y \\ Wang, H Hu, L Tang; (IV) Collection and assembly of data: X Zhao, R Xu, W Zhu, M Xiao; (V) Data analysis and interpretation: J Zhang, X Zhao; (VI) \\ Manuscript writing: All authors; (VII) Final approval of manuscript: All authors. \\ \#These authors contributed equally to this work. \\ Correspondence to: Cheng Guo; Zan Shen. Shanghai Jiao Tong University Affiliated Sixth People's Hospital, No. 600, Road Yishan, Shanghai 200233, \\ China. Email: guopharm@126.com; sshenzzan@vip.sina.com.
}

Background: Cancer has always been a serious health threat for human. Patients with cancer are at high risk of drug-related problems (DRPs) due to multi-morbidity associated polypharmacy. However, data is lacking in identifying and addressing potential DRPs in cancer patients in China. This study aims to investigate the prevalence of DRPs and evaluate the effectiveness of an independent anti-neoplastic medication therapy management (MTM) system in ambulatory cancer patients.

Methods: This is a retrospective study. An independent anti-neoplastic MTM system in Shanghai Jiao Tong University affiliated sixth People's Hospital was established in 2018 with the collaboration of oncologists, clinical pharmacists and software engineers. The system contains an independent clinic of pharmacy and MTM software. The software consisted of six modules to help clinical pharmacists serve the tumor patients. The six modules include medication therapy review, intervention plan, personal medication record, medication-related action plan, intervention and/or referral, and documentation and follow-up.

Results: A total of 173 eligible tumor patients visited the anti-neoplastic pharmaceutical clinic and were recorded in the independent anti-neoplastic MTM system from Jun 2018 to May 2019. The average clinic visits were 2.4 times of the study participants. Two thirds patients (117/173) had one or more identified DRPs in medication therapy review. Adverse drug reaction, potential drug interaction and non-adherence were the leading DRPs. $85.8 \%$ of DRPs could be resolved (cured or improved) in four weeks. Tumor patients showed medication adherence reached $84-100 \%$ after three or four times of follow-up and intervention.

Conclusions: The participation of clinical pharmacists in managing polypharmacy tumor patients, with the independent anti-neoplastic MTM system, facilitated the identifying and solving DRPs, especially improving medication adherence of patients, and thus enhancing the effectiveness, safety and rational use of medication.

Keywords: Cancer; medication therapy management (MTM); drug-related problems (DRPs); medication adherence; clinical pharmacist

Submitted Oct 29, 2020. Accepted for publication Feb 23, 2021.

doi: $10.21037 /$ tcr-20-3164

View this article at: http://dx.doi.org/10.21037/tcr-20-3164 


\section{Introduction}

The incidence of cancer has been increasing in most countries since the 1990s, and cancer has become the second leading cause of death in 2013 despite substantial progress has been made in prevention and treatment (1). From 2006 to 2016 , the number of people with cancer increased by $28 \%$ and reached 17.2 million worldwide, which resulted in 8.9 million deaths (2). This situation is particularly severe in developing countries whose health systems are usually deficient in cancer diagnosis and treatment $(1,3)$. By using the same methods of global burden of disease, eight types of cancer appeared in the 25 leading causes of death in China in 2017, and the estimated deaths for these eight types of cancer summed up to 148 deaths per 100,000 population (4). The trend of aging population and increasing number of long-term cancer survivors will increase the complexity of tumor patient management and severity to cancer morbidity and mortality (5).

Drug-related problem (DRP) is defined as, "an event or circumstance involving drug therapy that actually or potentially interferes with desired health outcomes" according to the pharmaceutical care network of Europe (PCNE) (6). Strong evidence had shown that negative health outcomes are associated with DRPs, such as increased healthcare costs, prolonged hospital stays, reduced quality of life, and increased mortality (7-9). Patients with cancer are at high risk of DRPs due to multi-morbidity associated polypharmacy. Since cancer is one of the medical conditions associated with aging (10), there is a high probability of cancer patients taking multiple medications, which can lead to overdose, potential drug interactions, and low medication adherence (11). Studies demonstrated that the intervention conducted by pharmacists could greatly improve the adherence rate of oral anti-neoplastic drugs, and ultimately improve the outcomes of oral chemotherapy $(12,13)$. A systematic review of studies about clinical medication review service in Australia confirmed that the significant role of pharmacists in improving the quality use of medications and health outcomes and advocated collaborations between different medical workers (14). However, few studies have been conducted in China on DRPs and pharmacists' role in them.

The patients with malignant tumor, especially those elderly and multiple therapeutics, are widely ignored in pharmaceutical care in China. In 2018, a guideline on development of pharmaceutical service was issued by National Health Commission of China, which requiring the role transformation and emphasizing the professional service provided by pharmacists (15). In the same year, the first anti-neoplastic pharmaceutical clinic in Shanghai was established to improve the medication adherence, promote drug rationally use and prevent adverse reactions. This clinic will serve tumor patients independently by following the mode of medication therapy management (MTM) service. We present the following article in accordance with the STROBE reporting checklist (available at http://dx.doi. org/10.21037/tcr-20-3164).

\section{Methods}

\section{Study design and development of independent anti- neoplastic MTM system}

The independent anti-neoplastic MTM system in Shanghai Jiao Tong University affiliated sixth People's Hospital was established in 2018 with the collaboration of oncologists, clinical pharmacists and software engineers. The system contains an independent clinic of pharmacy and MTM software. The MTM software (intellectual property registration No. 2018SR916520) was designed on the basis of the concept of patient-centered medication management service (16). The software consisted of six modules, namely medication therapy review (MTR), intervention plan, personal medication record (PMR), medication-related action plan (MAP), intervention and/or referral (I\&R), documentation and follow-up (DFU), and supplement scores for assessment in modules (Figure 1). Through MTM software the clinical pharmacists can retrieve the information from hospital information system and the structured data of medication history could be extracted automatically and presented in table format. As a result, the clinical pharmacists could manage the patients in a formulated structure, which improving the safety, compliance and ultimately the medications outcomes.

\section{Patient management procedure}

The main management procedure in this study was depicted in the flowchart (Figure 1). According to the registration, a patient's baseline information, treatment history, medication history, adverse events, health status and medical test records would be collected and retrieved. The clinical pharmacists can review the medication history in MTR module to evaluate the efficacy, safety, compliance and DRPs. The American Society of Hospital Pharmacist classification system for documenting DRPs and pharmacy interventions was applied in this study with 

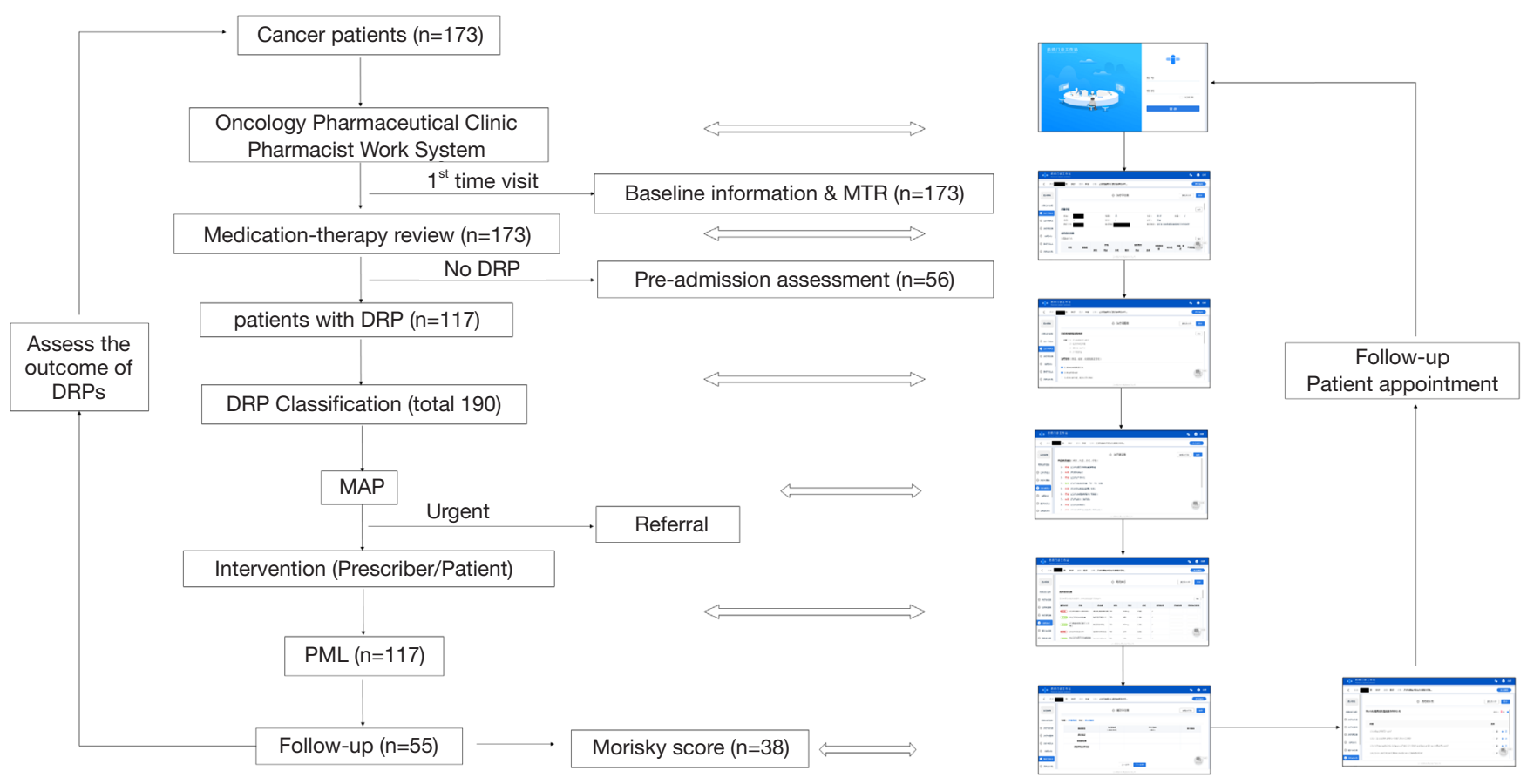

Figure 1 The scheme of patient flowchart in anti-neoplastic medication-therapy management

slight modifications $(17,18)$. Nine types of DRPs covering indications, effectiveness, safety and adherence, including (I) drug without indication; (II) indication without drug; (III) inappropriate drug; (IV) underdose; (V) adverse drug reaction; (VI) overdose; (VII) non-adherence; (VIII) potential drug interaction, and (IX) other problems. Those patients without DRPs, a pre-admission assessment will be conducted before hospital-based chemotherapy. For those with DRPs, a detailed medication-related action plan will be provided after reaching a consensus between clinical pharmacists and oncologists. Based upon the action plan the patients can learn about their own DRPs and be under surveillance through daily records. Questionnaires on knowledge, attitude and practice of medications or related problems will be collected during the patient management process (Table S1). According to the action plan the patients are scheduled to follow-up. The pharmacists review, assess and evaluate their laboratory tests and treatment outcomes of the DRPs (including cure, stable status, improved, partial improved, no improvement, deterioration, failure). The 8-item medication adherence scale (Chinese version) will be used to assess tumor patients with serious DRPs (19). And the score of $<6,6$ to 7 , and 8 is regarded as non-compliance, medium, and high adherence, respectively.

\section{Study patients}

Patients of any cancer type and stage admitted to antineoplastic pharmaceutical clinic, in Shanghai Jiao Tong University affiliated sixth People's Hospital, from Jun 2018 to May 2019 were retrospectively enrolled for MTM. In this retrospective analysis only patients who were followed up three and more times and received chemotherapy in our hospital, were assessed by the MMAS- 8 which scoring the medication compliance. The study was conducted in accordance with the Declaration of Helsinki (as revised in 2013). The study was approved by Ethics Committee of Shanghai Sixth People's Hospital (2013-44) and informed consent was taken from all the participants.

\section{Statistical analysis}

The data were collected during the patient management as depicted in the flowchart (Figure 1). Continuous data were expressed as mean with standard deviation, while categorical data was presented as count (percentage). The chi-square test or fisher exact test were used to compare the proportions of different groups. The DRPs data use time-to-event and the Kaplan-Meier method (defined as event $=1$ ). The patients whose MMAS- 8 score $\geq 6$ is regarded 
as acceptable adherence level (defined as event=1), and the median time of patients reached acceptable was estimated by using Kaplan-Meier method. A significant level of $\alpha=0.05$ was used in two tailed statistical test. Statistical analysis was performed by SPSS 21.0 (IBM Corp. Armonk, NY).

\section{Results}

\section{Patients' characteristics}

173 eligible patients were recorded and followed in the independent anti-neoplastic MTM system during this period (Figure 1). The tumor patients aged from 4 to 86 years with mean of $49.4( \pm 22.3)$ years, more than $60 \%$ participants are in 18-70 years. Among the population, one sixth patients were under 18 years and one fifth were over 70 years. Female patients accounted for 50\% (chi-square test, $\mathrm{P}=0.595)$. Five leading types of cancer were related to bone, lung, breast, colorectum and prostate. Nearly all the patients suffered from one or more comorbidities. 68 adverse drug reactions were identified by pharmacists, including very common adverse events such as constipation $(\mathrm{n}=13)$, myelosuppression $(\mathrm{n}=10)$ and drug-induced liver injury $(\mathrm{n}=8)$ (Table 1$)$.

\section{Patients follow-up}

Two thirds patients (117/173) had one or more identified DRPs through medication therapy review. These patients were scheduled to follow-up and re-evaluation, among which $47 \%$ (55/117) visited the MTM clinic more than one time. The average clinic visits were 2.4 times. A small portion of patients visited the MTM clinic more than ten times in a year (Figure 2).

\section{Improvement in patients with DRPs and non-adberence}

117 patients were identified with 190 DRPs in this study. Adverse drug reaction, potential drug interaction and nonadherence were the leading DRPs, with 35.8\% (68/190) were adverse drug reactions (Table 2). Among these DRPs, $85.8 \%$ (163/190) could be resolved (cured or improved), and 96 DRPs of 78 patients were cured and 67 DRPs of 58 patients were improved within median 6.8 and 27.8 days, respectively (Figure $3 A$ ). In this study, most majority of non-compliance $(27 / 29)$ had been improved. 38 patients with serious DRPs were assessed by experienced clinical pharmacists by using 8 -item medication adherence scale
(Chinese version). At the first time visit, only 24\% (9/38) tumor patients showed medication compliance according to medication adherence scale score $(\geq 6)$, then reached $66 \%$ $(25 / 38)$ at the second time visit, and $84 \%$ (32/38), $100 \%$ $(32 / 32)$ at third and fourth time visit, respectively. At the third visit, the improvement on compliance was significant with estimated median 35 days (Fisher exact test, $\mathrm{P}=0.0004$ ) (Figure 3B).

\section{Economic benefit}

One patient with colon cancer who also suffered from chronic renal dysfunction, whose glomerular filtration rate (GFR) was $40 \mathrm{~mL} / \mathrm{min} / 1.73 \mathrm{~m}^{2}$. And he was prescribed 21 different drugs on his first visit to the MTM clinic. After the multidisciplinary consultation of clinic pharmacists and oncologists, the final drugs list only contained 11 essential drugs with equivalent treatment efficacy. This cut the medication fee by $¥ 157.45$ each day ( $¥ 4,880.95$ per month) (Table S2). The data of economic benefit will be discussed elsewhere.

\section{Discussion}

It was estimated that more than 4.2 million people would be diagnosed with cancer and 2.8 million cancer deaths would occur in China in 2018 (3,20). A non-negligible and long-standing fact is that the oncologists are so busy that they have little time to educate, manage and schedule the optimized medication plan for every patient, especially those who also have other chronic diseases. As a result, the therapeutic effects would be decreased, with the DRPs or other secondary problems in chemotherapy would likely be ignored. In addition, polypharmacy and altered metabolic profile in tumor patients incline to suffer from the drug interactions, overdose and frequency of adverse drug reactions. On the other hand, the polypharmacy, comorbidity, aging might complicate the situation and contribute to under-prescribing $(21,22)$. So the oncologists eagerly expect the involvement of multi-disciplinary experts especially the pharmacists to manage the tumor patients to take medications (23-25).

Fortunately, our clinical pharmacists have been receiving training since the introduction of the MTM mode from USA in 2015 (26-28). In phase I, we established the first anti-neoplastic MTM system in Shanghai in 2018 with the cooperation of oncologists, clinic pharmacists and software engineers. This MTM system was also designed to facilitate 
Table 1 Baseline characteristics of tumor patients $(n=173)$

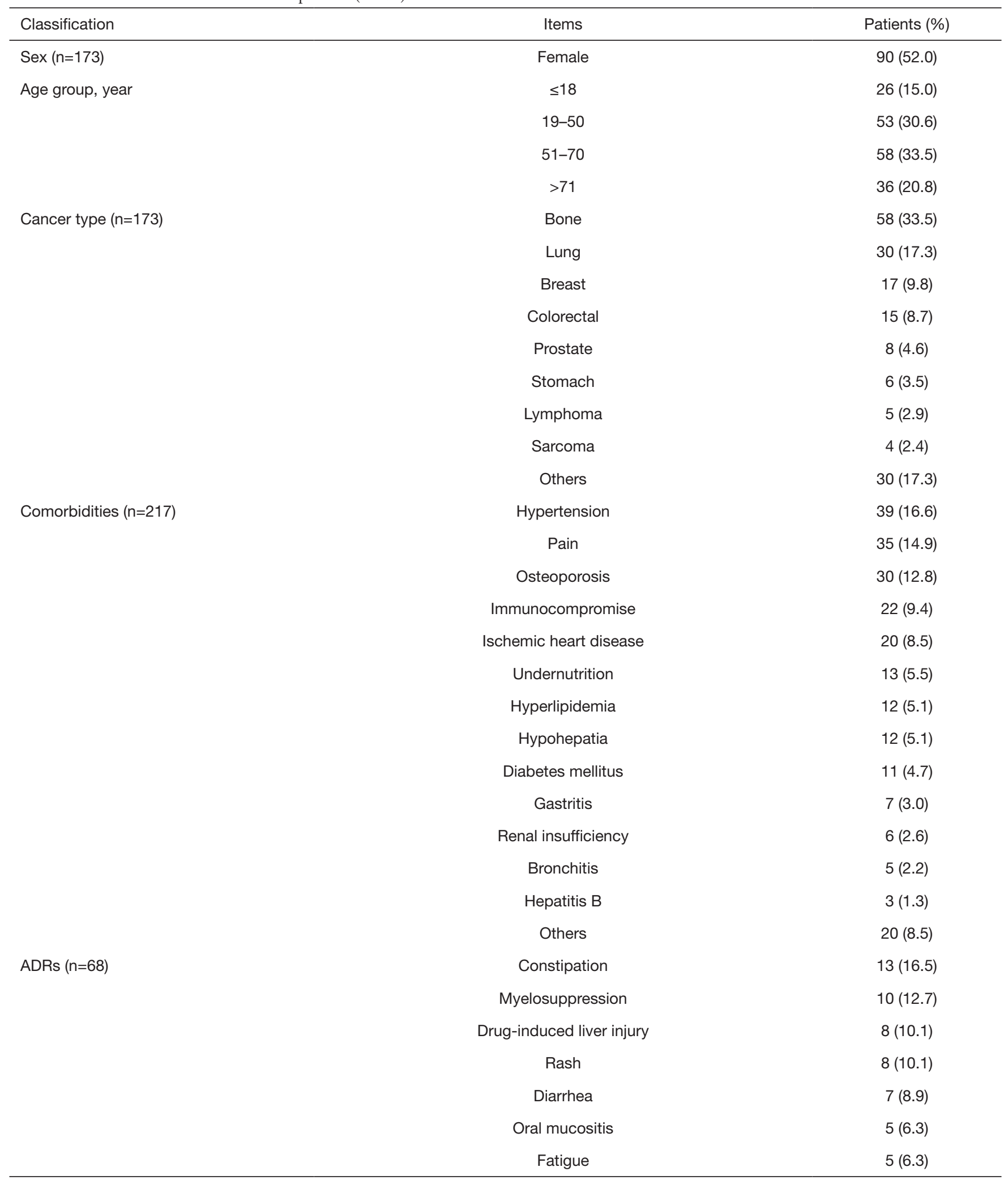

Table 1 (continued) 
Table 1 (continued)

\begin{tabular}{|c|c|c|}
\hline Classification & Items & Patients (\%) \\
\hline & Renal insufficiency & $5(6.3)$ \\
\hline & Hand foot syndrome & $5(6.3)$ \\
\hline & Anorexia & $4(5.1)$ \\
\hline & Proteinuria & $1(1.3)$ \\
\hline & peripheral sensory neuropathy & $1(1.3)$ \\
\hline
\end{tabular}

The comorbidities and adverse drug reactions (ADRs) was counted according to event.

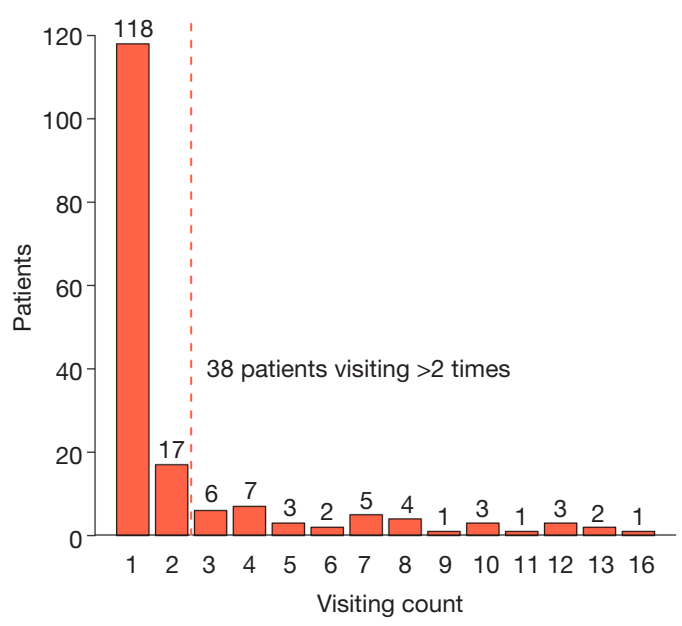

Figure 2 The distribution of patients' visit. The average clinic visits were 2.4 times, majority of patients visited once or twice, with 38/173 (22\%) patients visiting more than 2 times; few patients visited more than ten times within 1 year (Jun 6, 2018 to May 31, 2019).

the communication and cooperation of different medical workers, which has been proved to improve satisfaction and coordination of patient $(29,30)$. In the MTM system, pharmacists' role is to conduct medication review for cancer patients, record all medication, address drug counseling, provide recommendations and collaborate with physicians to improve the accuracy of medication regimens. This antineoplastic MTM system can be viewed as an extension of hospital information system, which differs from most prevalent MTM such as in United States of America, or commercial insurance agencies $(31,32)$. At present, few MTM systems focus on the medication record, medication action plan and patients' follow up (33). In phase II, we will
Table 2 Types of drug-related problems (DRPs) identified

\begin{tabular}{lc}
\hline Drug-related problems & Number (percentage) \\
\hline Adverse drug reaction & $68(35.8)$ \\
Potential drug interaction & $30(15.8)$ \\
Non-adherence & $29(15.3)$ \\
Others & $20(10.5)$ \\
Indication without drug & $19(10)$ \\
Overdose & $8(4.2)$ \\
Underdose & $7(3.7)$ \\
Drug without indication & $7(3.7)$ \\
Inappropriate drug & $2(1.0)$ \\
Total & $190(100.0)$ \\
\hline
\end{tabular}

incorporate the MTM system into the hospital medical system which would collect more medication information of patients. What's more, we obtained a patent on antineoplastic MTM system.

The MTM system is of great significance to the construction of the oncology pharmacy clinic. It is helpful for accurate screening of patients and integration of medication information. The information-based pharmaceutical tools significantly improve the work efficiency of clinical pharmacists and facilitate the workload statistics of pharmaceutical care. Electronic file management in the MTM system and individualized medication education have increased patients' satisfaction of pharmacy clinic. However, some limitations of the MTM system have to be considered. At present, the MTM system does not have online follow-up function after patients leave the 

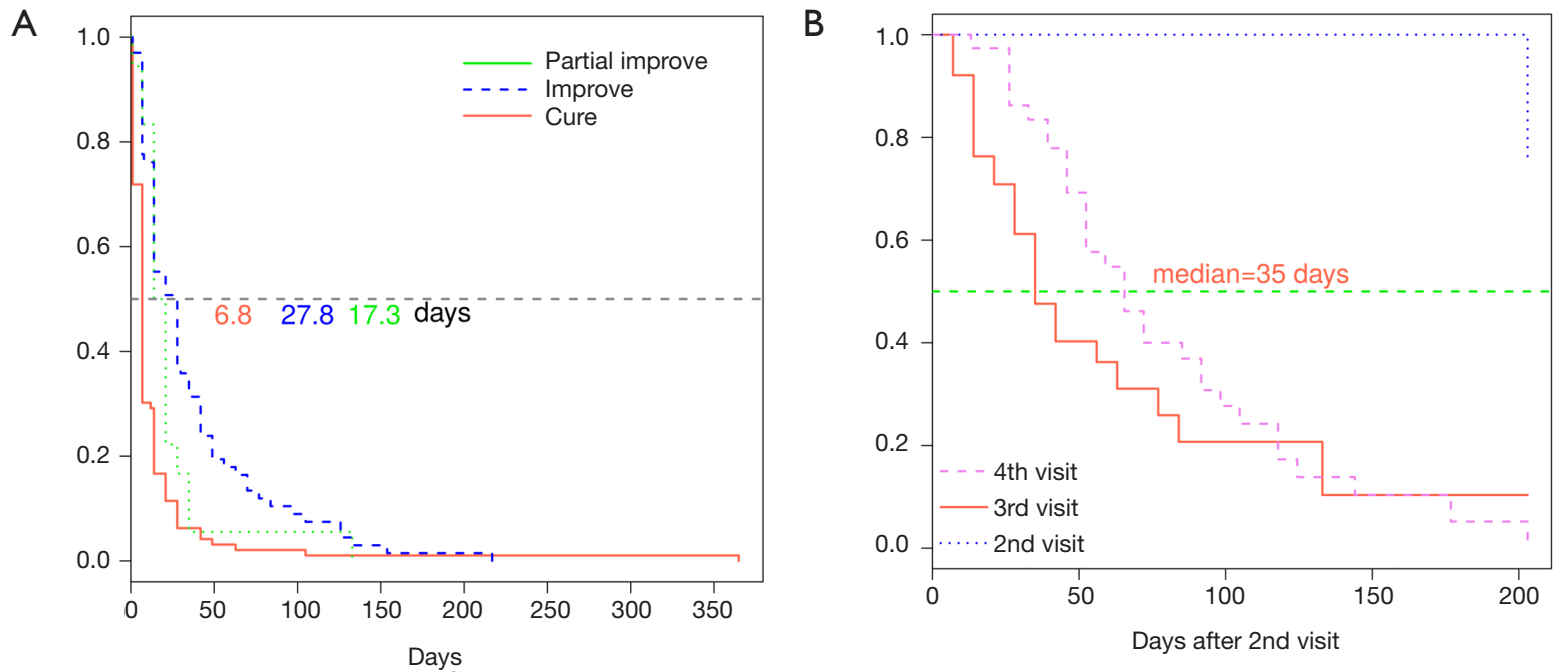

Figure 3 The improvement of patients with DRPs and compliance. (A) 96 DRPs of 78 patients were cured in median 6.8 days, and 67 DRPs of 58 patients were improved in median 27.8 days; (B) by defining the medication adherence scale score $\geq 6$ as satisfactory medication adherence (event $=1$ ), the patient adherence was improved significantly since the third visit with median 35 days (Fisher exact test, $\mathrm{P}=0.0004$ ).

hospital, which cannot meet the requirements of internet medical service. Since our pharmacy clinic is opened once a week for 4 hours each time, we can only serve $6-10$ patients each time in half a day per week.

Five leading types of cancer were related to bone, lung, breast, colorectum and prostate in our anti-neoplastic MTM system. This is different from the result of other domestic data which referred to the lung, liver, stomach, esophageal and colorectal cancer. This difference may be attribute to the fact that there are many patients with bone tumors in the department of orthopedics in our hospital. What should be of concern is that our tumor patients come from more than ten provinces in China. The geographic distribution will increase the difficulty of follow-up. The MTM system of phase II aims to overcome some known obstacles, facilitate the communication and integrate to current systems. In addition, we plan to serve more outpatients (34). Meanwhile we need more pharmacists to deal with redundant data $(25,35,36)$.

Studies certified that poor medication adherence would affect health outcomes and increase overall healthcare cost (27). In order to improve the patients' adherence, we provided the 8 -item medication adherence scale for patients who have serious DRPs. Though only the non-adherence account for $15 \%$, in fact it is more common in other studies $(37,38)$. Our findings suggest that the involvement of clinical pharmacists can help improve patient compliance, as in other studies $(39,40)$.
Currently, our sample size is small, the gene related data cannot be incorporated into the medication action plan and the MTM workstation has not been totally integrated into the whole process of patient management. However, through anti-neoplastic MTM practice our clinical pharmacists have achieved our important role in managing patient. Pharmacists should provide available pharmaceutical care to the public to promote the effectiveness, safety and rational use of medicines.

\section{Conclusions}

The first anti-neoplastic MTM system in Shanghai was established in Shanghai Jiao Tong University affiliated sixth People's Hospital with the multi-disciplinary collaboration. In a year of clinical pharmacists' involvement in tumor patients' MTM, $85.8 \%$ of DRPs could be resolved (cure or improved) in four weeks; the medication adherence reached $84-100 \%$ following three or four times of followup and intervention. Based on the current experience, the phase II aims to overcome some known obstacles, facilitate the communication and integrate to current systems, ultimately enhance the effectiveness, safety and rational use of medication.

\section{Acknowledgments}

We would like to acknowledge all the patients who 
participated in the study as well as all the warm-hearted peer support persons. In addition, this manuscript has been released as a pre-print at Research Square (Jianping Zhang et al, doi:10.21203/rs.2.18221/v1, https://www.researchsquare. com/article/rs-8845/v1). We thank Dr. Quanjun Yang for checking and editing the language of this paper.

Funding: This work was funded by the Shanghai Municipal Health Commission research project (Grant No. 2016ZB0302-01). However, the funding body had no role in the design of this study or in its execution, analyses, interpretation of the data, or decision to submit results.

\section{Footnote}

Reporting Checklist: The authors have completed the STROBE reporting checklist. Available at http://dx.doi. org/10.21037/tcr-20-3164

Data Sharing Statement: Available at http://dx.doi. org/10.21037/tcr-20-3164

Conflicts of Interest: All authors have completed the ICMJE uniform disclosure form (available at http://dx.doi. org/10.21037/tcr-20-3164). The authors have no conflicts of interest to declare.

Ethical Statement: The authors are accountable for all aspects of the work in ensuring that questions related to the accuracy or integrity of any part of the work are appropriately investigated and resolved. The study was conducted in accordance with the Declaration of Helsinki (as revised in 2013). The study was approved by Ethics Committee of Shanghai Sixth People's Hospital (2013-44) and informed consent was taken from all the participants.

Open Access Statement: This is an Open Access article distributed in accordance with the Creative Commons Attribution-NonCommercial-NoDerivs 4.0 International License (CC BY-NC-ND 4.0), which permits the noncommercial replication and distribution of the article with the strict proviso that no changes or edits are made and the original work is properly cited (including links to both the formal publication through the relevant DOI and the license). See: https://creativecommons.org/licenses/by-nc-nd/4.0/.

\section{References}

1. Fitzmaurice C, Dicker D, Pain A, et al. The Global
Burden of Cancer 2013. JAMA Oncol 2015;1:505-27. Erratum in: JAMA Oncol 2015;1:690.

2. Fitzmaurice C, Akinyemiju TF, Al Lami FH, et al. Global, Regional, and National Cancer Incidence, Mortality, Years of Life Lost, Years Lived With Disability, and DisabilityAdjusted Life-Years for 29 Cancer Groups, 1990 to 2016: A Systematic Analysis for the Global Burden of Disease Study. JAMA Oncol 2018;4:1553-68.

3. Chen $W$, Zheng R, Baade PD, et al. Cancer statistics in China, 2015. CA Cancer J Clin 2016;66:115-32.

4. Zhou M, Wang H, Zeng X, et al. Mortality, morbidity, and risk factors in China and its provinces, 1990-2017: a systematic analysis for the Global Burden of Disease Study 2017. Lancet 2019;394:1145-58.

5. Carmona-Bayonas A, Jimenez-Fonseca P, Castanon E, et al. Chronic opioid therapy in long-term cancer survivors. Clin Transl Oncol 2017;19:236-50.

6. Pharmaceutical Care Network Europe Foundation, Classification for Drug Related Problems Revised V 8.01, Pharmaceutical Care Network Europe Foundation. Zuidlaren, Netherlands, 2017.

7. Alomi YA, Al-Shaibani AS, Alfaisal G, et al. Clinical outcomes of drug-related problems in Saudi Arabia: patients' and healthcare providers' perspective. J Pharm Prac Community Med 2018;4:77-82.

8. Naples JG, Hanlon JT, Schmader KE, et al. Recent literature on medication errors and adverse drug events in older adults. J Am Geriatr Soc 2016;64:401-8.

9. Salvi F, Marchetti A, D'Angelo F, et al. Adverse drug events as a cause of hospitalization in older adults. Drug Saf 2012;35:29-45.

10. Yap KY, Chia Y, Low XH, et al. Technological preferences of aging cancer patients for delivery services and devices to solve drug-related problems in oncology. Support Care Cancer 2014; 22:2733-40.

11. Jaehde U, Liekweg A, Simons S, et al. Minimising treatment-associated risks in systemic cancer therapy. Pharm World Sci 2008;30:161-8.

12. Felton MA, van Londen GJ, Marcum ZA. Medication adherence to oral cancer therapy: The promising role of the pharmacist. J Oncol Pharm Pract 2016;22:378-81.

13. Simons S, Ringsdorf S, Braun M, et al. Enhancing adherence to capecitabine chemotherapy by means of multidisciplinary pharmaceutical care. Support Care Cancer 2011;19:1009-18.

14. Jokanovic N, Tan EC, van den Bosch D, et al. Clinical medication review in Australia: A systematic review. Res Social Adm Pharm 2016;12:384-418. 
15. Opinions on accelerating the quality development of pharmaceutical services. Available online: http://www.gov. cn/xinwen/2018-11/28/content_5344128.htm. Accessed 8 October 2020.

16. Robert J. Cipolle LMS, Peter C. Morley. Pharmaceutical Care Practice: The Patient-Centered Approach to Medication Management. 3rd ed. New York: McGrawHill Education, 2012.

17. Hepler CD, Strand LM. Opportunities and responsibilities in pharmaceutical care. Am J Hosp Pharm 1990;47:533-43.

18. Draft statement on pharmaceutical care. ASHP Council on Professional affairs. American Society of Hospital Pharmacists. Am J Hosp Pharm 1993;50:126-8.

19. Tsai YF, Huang WC, Cho SF, et al. Side effects and medication adherence of tyrosine kinase inhibitors for patients with chronic myeloid leukemia in Taiwan. Medicine 2018;97:e11322.

20. Cancer Today. Available online: http://gco.iarc.fr/today/ explore. Accessed 8 October 2020.

21. Cherubini A, Corsonello A, Lattanzio F. Underprescription of beneficial medicines in older people: causes, consequences and prevention. Drugs Aging 2012;29:463-75.

22. Andrade SE, Kahler KH, Frech F, et al. Methods for evaluation of medication adherence and persistence using automated databases. Pharmacoepidemiol Drug Saf 2006;15:565-74.

23. Shea BJ, Grimshaw JM, Wells GA, et al. Development of AMSTAR: a measurement tool to assess the methodological quality of systematic reviews. BMC Med Res Methodol 2007;7:10.

24. Dunn SP, Birtcher KK, Beavers CJ, et al. The role of the clinical pharmacist in the care of patients with cardiovascular disease. J Am Coll Cardiol 2015;66:2129-39.

25. Mensah KB, Oosthuizen F, Bonsu AB. Cancer awareness among community pharmacist: a systematic review. BMC Cancer 2018;18:299.

26. China MTM training. Available online: http://cmtm. cmtms.cn/info/cmtm.html. Accessed 8 October 2020.

27. Iuga $\mathrm{AO}, \mathrm{McGuire} \mathrm{MJ}$. Adherence and health care costs. Risk Manag Healthc Policy 2014;7:35-44.

28. Spivey CA, Qiao Y, Wang J, et al. Comparative Effectiveness of Medication Therapy Management Eligibility Criteria Across Racial/Ethnic Groups. J Am Geriatr Soc 2019;67:581-7.

29. Dossett LA, Hudson JN, Morris AM, et al. The primary care provider (PCP)-cancer specialist relationship: A systematic review and mixed-methods meta-synthesis. CA Cancer J Clin 2017;67:156-69.

30. Carter SR, Moles R, White L, et al. The impact of patients' perceptions of the listening skills of the pharmacist on their willingness to re-use Home Medicines Reviews: a structural equation model. Res Social Adm Pharm 2015;11:163-75.

31. Smith MA, Spiggle S, McConnell B. Strategies for community-based medication management services in valuebased health plans. Res Social Adm Pharm 2017;13:48-62.

32. Medication management solutions. Available online: https://www.genoahealthcare.com/medicationmanagement-solutions. Accessed 8 October 2020.

33. Gernant SA, Nguyen MO, Siddiqui S, et al. Use of pharmacy technicians in elements of medication therapy management delivery: A systematic review. Res Social Adm Pharm 2018;14:883-90.

34. Koyama T, Onoue H, Ohshima A, et al. Trends in the medication reviews of community pharmacies in Japan: a nationwide retrospective study. Int J Clin Pharm 2018;40:101-8.

35. Gerhards NM, Rottenberg S. New tools for old drugs: Functional genetic screens to optimize current chemotherapy. Drug Resist Updat 2018;36:30-46.

36. Chang AR, Evans M, Yule C, et al. Using pharmacists to improve risk stratification and management of stage $3 \mathrm{~A}$ chronic kidney disease: a feasibility study. BMC Nephrol 2016;17:168.

37. Yeoh TT, Tay XY, Si P, et al. Drug-related problems in elderly patients with cancer receiving outpatient chemotherapy. J Geriatr Oncol 2015;6:280-7.

38. Ritchie CS, Kvale E, Fisch MJ. Multimorbidity: an issue of growing importance for oncologists. J Oncol Pract 2011;7:371-4.

39. Bisharat B, Hafi L, Baron-Epel O, et al. Pharmacist counseling to cardiac patients in Israel prior to discharge from hospital contribute to increasing patient's medication adherence closing gaps and improving outcomes. J Transl Med 2012;10:34.

40. Huiskes VJ, Burger DM, van den Ende CH, et al. Effectiveness of medication review: a systematic review and meta-analysis of randomized controlled trials. BMC Fam Pract 2017;18:5.

Cite this article as: Zhang $\mathrm{J}, \mathrm{Xu} \mathrm{R}$, Zhao X, Wang Y, Zhu W, Xiao M, Hu H, Tang L, Shen Z, Guo C. The effectiveness of an independent anti-neoplastic medication therapy management system in ambulatory cancer patients. Transl Cancer Res 2021;10(4):1703-1711. doi: 10.21037/tcr-20-3164 


\section{Supplementary}

Table S1 Pharmaceutical service intention survey

Q1 Where do you get information about cancer-related diseases and medicines? (multiple choice)

$\square$ doctor or nurse; $\quad \square$ professional books, journals; $\quad \square$ internet, magazine;

$\square$ pharmacist; $\quad \square$ WeChat (eg: Pharmacy of the Sixth Hospital);

$\square$ friends and family (other than healthcare professionals);

$\square \mathrm{TV}$ (such as health programs, advertising); $\quad \square$ other

Q2 Have you consulted the pharmacist about medication?

(yes, continue to 3; no, skip to Q4)

$\square$ Yes $\quad$ No

Q3 What aspects of information do you consult with pharmacists mainly? (multiple choice)

$\square$ does the pharmacy have some special anti-tumor drugs?

$\square$ drug usage and indications;

$\square$ adverse drug reactions and side effects;

$\square$ questions about multiple medications or drug-drug interaction;

$\square$ other

Q4 What kind of pharmaceutical services do you need from pharmacists? (multiple choice)

$\square$ inquiry for basic information of drugs;

$\square$ questions on adverse drug reaction;

$\square$ questions on drug usage and dosage;

$\square$ questions on multiple medications, drug-drug interaction;

$\square$ to prevent the adverse drug reactions;

$\square$ lecture information on drug safety;

$\square$ other (you need)

Q5 If we lecturing on medication knowledge, will you attend?

$\square$ Yes $\square$ at my spare time $\quad \square$ No

Q6 Did you accept telephone call from us?

$\square$ Yes $\square$ No

Q7 Would you like to join the WeChat group hosted by pharmacists of Shanghai Sixth People's Hospital and to share your medication experience with other patients and pharmacists?

$\square$ Yes $\square$ No

Q8 Did you satisfy the service provided by the pharmacist?

$\square$ satisfied $\quad \square$ ordinary level $\square$ not satisfied 
Table S2 A case of medication list modification after the effort both of clinical pharmacists and oncologists

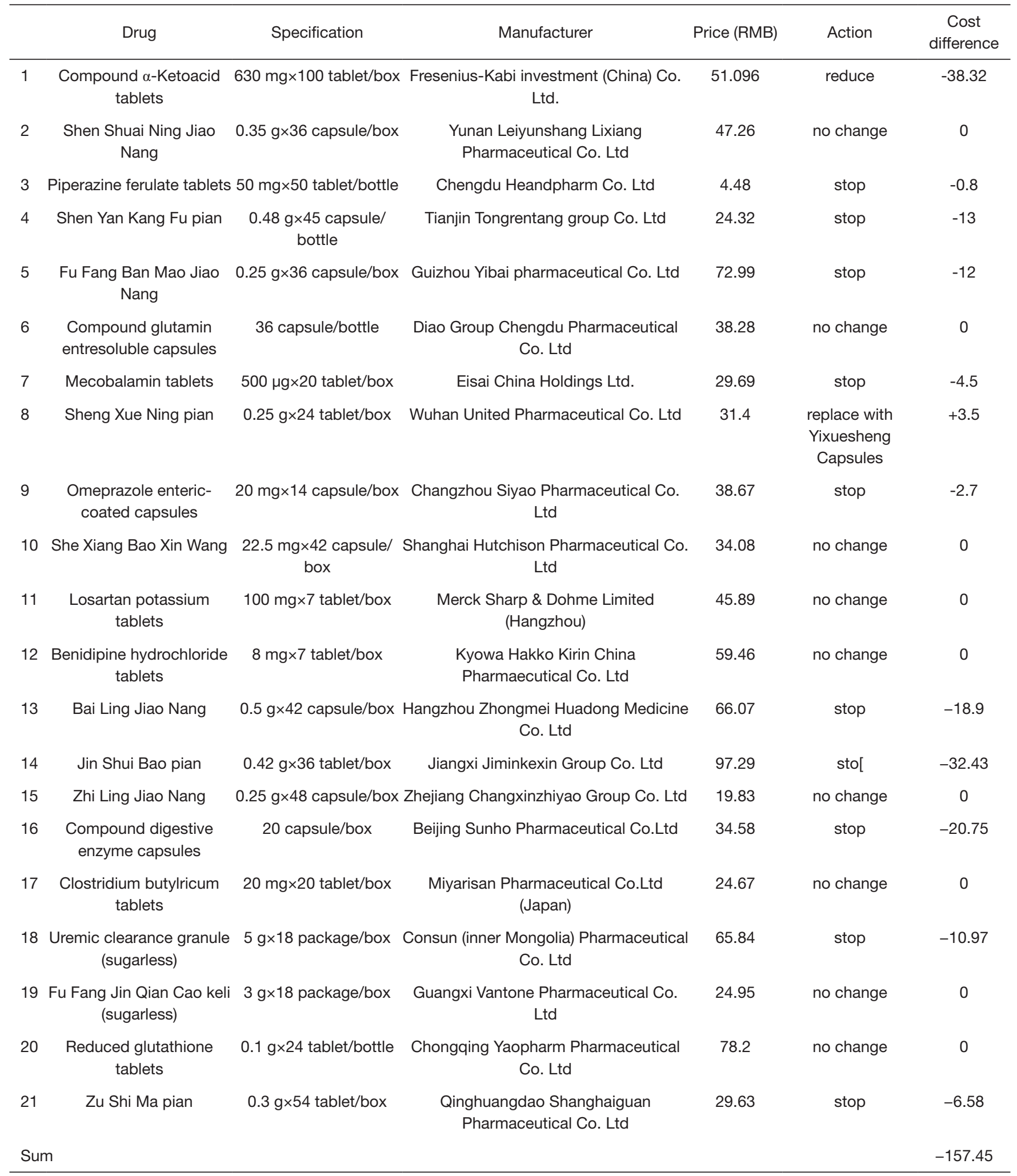

